Gut, 1984, 25, 445-447

\title{
Colorectal screening by a self-completion questionnaire
}

\author{
P A FARRANDS AND J D HARDCASTLE \\ From the Department of Surgery, Southampton General Hospital, Southampton
}

SUMmARY The prevalence and significance of colorectal symptoms within a group of 1533 individuals was assessed using a self-completion questionnaire and results compared with faecal occult blood screening. One hundred and twenty eight individuals listed one or more symptoms, while only 12 had a positive blood occult test. Of the subjects studied, $6.6 \%$ had noticed bleeding from the rectum in the last six months, $8.7 \%$ diarrhoea, and $12.3 \%$ a change in bowel habit. Examination of these individuals revealed one $(0.8 \%)$ to have an adenoma of the colon. By comparison, occult blood testing identified two patients with carcinoma and four with adenoma. Both of the patients with carcinoma and three out of the four with adenoma had replied negative to the questionnaire suggesting the self-completion questionnaire to be of little value in the early detection of colorectal neoplasia.

Screening of asymptomatic individuals for colorectal cancer has been attempted using rigid sigmoidoscopy ${ }^{1}$ or the stabilised quaiac faecal occult blood test. Haemoccult (Eaton Laboratories). ${ }^{2}{ }^{3}$ Each technique had disadvantages. Rigid sigmoidoscopy only examines the distal bowel and faecal occult blood testing is hampered by appreciable false negative rate. ${ }^{+}$and a poor compliance. ${ }^{5-7}$

The median time from the onset of symptoms to diagnosis of colorectal cancer is 30-32 weeks. Eighty per cent of this delay being before the patient is seen at the hospital. ${ }^{8}$ Furthermore, of those patients admitted to hospital as emergencies $(40 \%) 75 \%$ have seen their general practitioner with symptoms before their urgent admission. ${ }^{8}$ Early identification of these symptomatic individuals may be a more beneficial method of screening than extensive screening of asymptomatic individuals. The aim of this study was to determine the prevalence of colorectal symptoms within the community, the significance of such symptoms as identified by a self-completion questionnaire, and to correlate the results of the self-completion questionnaire with standard occult blood testing.

\footnotetext{
Methods

PATIENTS

One thousand five hundred and thirty three patients

Address for correspondence: Mr P Farrands. FRCS. University Surgical Unit. F Level. Centre Block. Southampton General Hospital. Tremona Road. Southampton SO1 6HU.

Received for publication 18 July 1983
}

aged between 45-74 years, from two general practices in Nottinghamshire, were studied. Those with known colorectal pathology were excluded by their general practitioner. Each patient was sent a self-completion questionnaire (Table 1) and a Haemoccult faecal occult blood test. Participants were asked to ring any of the symptoms listed that they had noticed in the last six months, and apply two samples from three successive stool specimens to the Haemoccult test slides (as recommended by the manufacturers, Eaton Laboratories). Dietary restrictions were not imposed but participants were told to avoid vitamin $\mathrm{C}$ preparations during the occult blood testing. Patients were provided with a stamped addressed envelope for return of the test

Table 1 Prevalence of symptoms in 527 individuals completing the questionnaire

\begin{tabular}{lcc}
\hline $\begin{array}{l}\text { Symptom } \\
\text { (1) Diarrhoea - either (a) watery } \\
\text { stools. or (b) more than three } \\
\text { bowel actions each day lasting } \\
\text { for more than one week }\end{array}$ & 46 & \\
$\begin{array}{l}\text { (2) Altered bowel habit: a change in } \\
\text { the number of bowel actions } \\
\text { (motions) }\end{array}$ & 65 & 8.7 \\
$\begin{array}{l}\text { (3) Bleeding from the back passage } \\
\text { (rectum) }\end{array}$ & 35 & 12.3 \\
(4) Weight loss without dieting of \\
$\quad \begin{array}{l}\text { more than 3.1 kg } \\
\text { (5) Abdominal pain that has worried } \\
\text { you }\end{array}$
\end{tabular}


and the Haemoccult slides were tested without rehydration. Any patient with one or more positive occult blood test, or a positive questionnaire (defined as one or more positive symptoms) was seen and examined in the Department of Surgery, where a rigid sigmoidoscopy and flexible sigmoidoscopy (using the $60 \mathrm{~cm}$ ACM.TS instrument) was performed. If no abnormality was found after flexible sigmoidoscopy, patients then underwent double contrast barium enema examination of the colon.

\section{Results}

Four hundred and eighty three $(34.3 \%)$ individuals returned both the questionnaire and the completed Haemoccult test, and a further 44 returned only the questionnaire, providing a total of 527 questionnaires for analysis (50 were returned as 'incorrectly addressed $(3 \cdot 2 \%))$.

One hundred and twenty eight $(24.4 \%)$ of the 527 questionnaires were positive (defined as one or more questions marked 'Yes'). Twelve $(2.5 \%)$ of the 483 Haemoccult tests were positive, eight being in asymptomatic patients and four in patients with symptoms (Table 2).

Of the 399 individuals with a negative questionnaire, 347 also had a negative Haemoccult test result, and only eight a positive Haemoccult test. Of the 128 individuals with a positive questionnaire. only four had a positive occult blood test (Table 3 ).

Forty six $(8.7 \%)$ out of the 527 individuals had had diarrhoea, $65(12.3 \%)$ a change in the number or type of bowel action, and $35(6.6 \%)$ bleeding from the back passage. Only three individuals had lost more than $3.1 \mathrm{~kg}$ in weight and $57(10.8 \%)$ had had abdominal pain that had worried them (Table $1)$.

Results of the examination of the 128 symptomatic individuals are shown in Table 4. A large number of subjects had had symptoms which had resolved by the time they were seen. No carcinomas

Table 2 Yield from 527 returned questionnaires

\begin{tabular}{lcr}
\hline Category & Number & \multicolumn{1}{c}{$\%$} \\
\hline Completed questionnaire +ve & 128 & 24.4 \\
Completed questionnaire - ve & 399 & $75 \cdot 6$ \\
Total & 527 & $10(0 \cdot 0$ \\
& & \\
Yield from 483 completed & & \\
Haemoccult tests in the & & \\
same patients & 12 & \\
$\quad$ Haemoccult test +ve & 471 & \\
$\quad$ Haemoccult test - ve & & \\
\hline
\end{tabular}

Table 3 Correlation of questionnaires with Haemoccult

\begin{tabular}{lrc}
\hline & Number & $\%$ \\
\hline Questionnaire completed: asymptomatic & & \\
Haemoccult completed - ve & 347 & $65 \cdot 8$ \\
Haemoccult completed +ve & 8 & 1.5 \\
Haemoccult not completed & 44 & $8 \cdot 3$ \\
Questionnaire completed: symptomatic & & \\
Haemoccult completed - ve & 124 & 23.5 \\
Haemoccult completed +ve & 4 & 0.75 \\
Total & 527 & $1(0) \cdot 0$ \\
\hline
\end{tabular}

were discovered in this group, but one individual who had noticed bleeding per rectum was found to have two $0.5-1.0 \mathrm{~cm}$ adenomatous polyps in the sigmoid colon (positive on Haemoccult testing). Other causes of bleeding per rectum were haemorrhoids $25(71.4 \%)$, diverticular disease four, fissure in ano one, and no abnormality was found after endoscopy and double contrast barium enema examination in four.

An examination of the 12 persons with a positive occult blood test (Table 5) revealed four patients to have one or more adenomatous polyps all over 0.5 $\mathrm{cm}$ in size, and two to have carcinomas of the sigmoid colon, one a Dukes' stage A and the other a Dukes' stage B lesion. Three of the patients with polyps and both patients with cancer had filled in 'negative' answers to all five of the questions on the questionnaire.

\section{Discussion}

Results from this study clearly show the questionnaire used was of little value in the identification of

Table 4 Results of 128 patients with positive questionnaire

\begin{tabular}{lc}
\hline Category & Number \\
\hline Adenomatous polyp (1 patient Haemoccult $+\mathrm{ve}$ ) & 1 \\
Haemorrhoids & 25 \\
Irritable bowel & 5 \\
Divcrticular disease (1 patient Haemoccult $+\mathrm{ve}$ ) & 6 \\
Duodenal ulcer & 3 \\
Constipated & 2 \\
Gastroenteritis & 2 \\
Fissure-in-ano & 1 \\
Postcholecystectomy & 1 \\
Left inguinal hernia & 1 \\
Past history of adenomatous polyp & 1 \\
Normal exmination (2 patients Haemoccult $+\mathrm{ve}$ ) & 56 \\
& 104 \\
Did not attend for examination & 24 \\
Total & 128 \\
\hline * A total of four patients with a positive Haemoccult blood test.
\end{tabular}


Table 5 Results of 12 patients with positive Haemoccult test and their questionnaire result

\begin{tabular}{llll}
\hline Patient & $Q$ & $H$ & Findings \\
\hline 1 & - & $+6 / 6$ & Ca sigmoid (B) \\
2 & - & $+3 / 6$ & Ca sigmoid (A) \\
3 & - & $+2 / 6$ & Polyp sigmoid $(2 \mathrm{~cm})$ \\
4 & - & $+1 / 6$ & Polyp $(2 \mathrm{~cm})$ \\
5 & - & $+2 / 6$ & 5 polyps $(1-2 \mathrm{~cm})$ \\
6 & - & $+1 / 6$ & Diverticular disease \\
7 & - & $+3 / 6$ & NAD \\
8 & - & $+1 / 6$ & NAD \\
9 & + & $+1 / 6$ & 2 polyps $(0 \cdot 5-1 \mathrm{~cm})$ \\
10 & + & $+1 / 6$ & Diverticular disease \\
11 & + & $+1 / 6$ & NAD \\
12 & + & $+1 / 6$ & NAD \\
\hline
\end{tabular}

$\mathrm{Q}=$ questionnaire, positive or negative.

$\mathrm{H}=$ Haemoccult test. number of squares positive.

early colorectal neoplasia. Not only was the false negative rate high, only one person out of the 128 with symptoms having neoplastic disease $(0.8 \%)$, but the false negative rate was also unacceptable $(83.3 \%)$ both of the patients with cancer and three out of the four with adenomas replying negatively to all five of the questions on the questionnaire.

Cancers of the colon and rectum produce symptoms of bleeding, diarrhoea, constipation, a change in the bowel habit and abdominal pain. Such symptoms, however, are extremely common within the general population as a whole. ${ }^{9-10}$ Of the subjects studied, $24.4 \%$ admitted to suffering from one of these symptoms; $6.6 \%$ of subjects admitting to bleeding from the rectum; $8.7 \%$ diarrhoea, $12.3 \%$ altered bowel habit, and $10.8 \%$ abdominal pain. These results have been confirmed by previous workers and show how difficult early identification of patients with neoplastic disease is, when so many apparently healthy subjects have such symptoms. Even the presence of bleeding from the rectum, a symptom present in a great many cancers, was only present in one of the patients with an adenoma, and more often than not was because of haemorrhoids; $71 \%$ of persons with bleeding being found to have haemorrhoids on examination, and it is understandable why so many clinicians attribute bleeding from the rectum to piles without further recourse.

Of more concern is the problem of the high false negative rate of the questionnaire in patients with neoplastic disease of the colon $(83.3 \%)$. Failure of the questionnaire may be due to the inability of individuals to recognise early subtle changes produced by the cancer or adenomas or a failure to ask the correct questions in the questionnaire. The frequency of symptoms detected by the questionnaire is similar to results obtained by Thompson and
Heaton, ${ }^{9}$ and Jones ${ }^{10}$ suggesting the questionnaire was reflecting the true frequency of symptoms noticed by the patients. It is much more likely, therefore, that the high false negative rate is due to the inability of most individuals to recognise early symptoms attributable to colorectal cancer and it is not until the cancer enlarges that their symptoms become apparent. For this reason the value of a self-completion questionnaire must remain limited as a method of screening for colorectal cancer, and occult blood testing despite its problems, remains the only practical method of population screening for colorectal cancer at the present time. The positive rate is low $(2.5 \%)$, but the predictive yield for neoplasia high $(50 \%)$; two patients with cancer, one a stage $A$ and one a stage $B$ and four patients with adenoma being identified.

\section{References}

1 Bond JH, Gilbertson VA. Early detection of colonic carcinoma by mass screening for occult stool blood. Preliminary report. Gastroenterology 1977: 72: 1031.

2 Winawer SJ, Leidner SD. Miller DG et al. Results of a screening programme for the detection of early colon cancer and polyps using faécal occult blood testing. [Abstract] Gastroenterology 1977: 72; A127: 1150.

3 Schwartz FW. Holstein H. Brecht JG. Preliminary report of faecal occult blood testing in Germany. In: Winawer SJ, Schottenfeld D, Sherlock P. eds. Colorectal cancer: prevention, epidemiology and screening. New York: Raven Press, 1980: 267-70.

4 Macrae FA. St Johns DJB. Relationship between patterns of bleeding and Haemoccult sensitivity in patients with colorectal cancer or adenomas. Gastroenterology 1982: 82: 891-8.

5 Winchester DP. Shull JH. Scanlon EF et al. A mass screening program for colorectal cancer using chemical testing for occult blood in the stool. Cancer 1980; 45: 2955-8.

6 Farrands PA, Griffiths RL. Britton DC. A practical solution to the diagnosis and treatment of colorectal cancer? Lancet 1981; 1: 1231-2.

7 Hardcastle JD, Balfour TW, Amar SS. Screening for symptomless colorectal cancer by testing for occult blood in general practice. Lancet 1980; 1: 791-3.

8 Holliday HW. Hardcastle JD. Delay in diagnosis and treatment of symptomatic colorectal cancer. Lancet 1979: 1: 309-11.

9 Thompson WG. Heaton KW. Functional bowel disorders in apparently healthy people. Gastroenterology 1980: 79: 283-8.

10 Jones ISC. An analysis of bowel habit, its significance in the diagnosis of carcinoma of the colon. $A m ~ J$ Proctol 1976: 27: 45-6. 


\section{Correspondence}

\section{Gastrointestinal carcinoid tumours}

SIR, - Rees et al (Gut 1984; 25: 211-7) present a patient with massive bleeding from an ileal carcinoid diagnosed by colonoscopy. We would like to present a similar case in which colonoscopy would not have aided the diagnosis and to add our experience of gastrointestinal carcinoids.

A 56 year old man was admitted to the Royal United Hospital in Bath with a four day history of passing both dark red blood and melaena per rectum. He had long standing hypertension in the presence of a hydronephrotic horse shoe kidney which was well controlled on Minoxidil $40 \mathrm{mg}$, Atenolol $400 \mathrm{mg}$ with chlorthalidone $100 \mathrm{mg}$ daily. There was no history of haematemesis nor abdominal pain, neither was there a history of flushing, diarrhoea, nor attacks of wheezing. On admission, his pulse was 100 , blood pressure $140 / 80$ $\mathrm{mmHg}$. He was not clinically shocked although his haemoglobin was $8.0 \mathrm{~g} / \mathrm{dl}$. During that day he was transfused three units of whole blood and his observations remained stable until the early evening when he became shocked (pulse rate 130, blood pressure $80 / 50 \mathrm{mmHg}$ ). This was accompanied by profuse dark red rectal bleeding. He was given a further five units of whole blood and an upper gastrointestinal endoscopy was performed urgently which was completely normal with no blood in the stomach. It was technically impossible to enter the duodenum. Further deterioration precluded angiography and a laparotomy was undertaken immediately. In the terminal ileum, a small $1 \mathrm{~cm}$ pedunculated lesion was noted. Blood was present for $15 \mathrm{~cm}$ proximal to this lesion and throughout the small and large bowel distal to the lesion. Several other nodules were present for $6 \mathrm{~cm}$ either side of the lesion, and there were enlarged glands in the mesentery. The liver contained one small nodule. A $20 \mathrm{~cm}$ resection of small bowel was carried out taking all the macroscopically obvious lesions with the mesenteric glands. The continuity of the small bowel was restored by end to end anastomosis, and the small nodule in the liver was excised. Histology confirmed the presence of carcinoid tumour in the small bowel, mesenteric nodes and in the liver.

Postoperatively he made an uncomplicated recovery and he was discharged on the 12th day after his operation having had no further rectal bleeding.

His blood pressure continues to be well controlled on the above anti-hypertensive regimen. At no stage has he exhibited the features of the carcinoid syndrome, with flushing, diarrhoea, nor bronchospasm.
We agree that such small tumours are difficult to diagnose before surgical exploration. This is reflected on reviewing 27 cases of gastrointestinal carcinoids in Bath from 1970-1983 (unpublished data). Of the 15 non-appendiceal tumours $40 \%$ presented with features of the carcinoid syndrome implying metastatic disease. Massive gastrointestinal bleeding is increasingly reported in the literature ${ }^{12}$ as a presenting feature of carcinoid tumours and should perhaps no longer be regarded as rare. The above case represents $6 \%$ of our small series compared to $9 \%$ according to Zeitels et al. ${ }^{3}$ The other presenting features in our series were those of small bowel obstruction (five), small bowel perforation (one), incidental to Crohn's stricture (one) and as diarrhoea due to a rectal polyp (one).

Small bowel carcinoids are therefore likely to remain elusive to diagnosis before metastatic spread or laparotomy despite such advances as colonoscopy. Gastrointestinal bleeding has favoured early diagnosis as in Rees et al, but this was not so in our case where regional and distant metastases had occurred so reducing his expected five year survival from the $75 \%$ for ileal carcinoids quoted by Godwin: ${ }^{4}$

M S HAMILTON,

Royal United Hospital,

D CRANSTON, AND K LLOYD-WILLIAMS

Bath.

\section{References}

1 Schwartz GF. Carcinoid tumours of the small intestine associated with acute gastrointestinal haemorrhage. $\mathrm{Am}$ J Surg 1966; 111: 553-4.

2 Hui K, Reza MJ, Busuttil RW. An unusual case of massive gastrointestinal haemorrhage. JAMA 1978; 239: 2690-1.

3 Zeitels J, Naunheim K, Kaplan EL, Strauss F. Carcinoid tumours - a 37 year experience. Arch Surg 1982; 117: 732-7.

4 Godwin JD. Carcinoid tumours - an analysis of 2,837 cases. Cancer 1975; 36: 560-9.

\section{Correction}

Colorectal screening by a self-completion questionnaire. (Gut 1984; 25: 445-7) Farrands and Hardcastle. The work on this paper was performed in the Department of Surgery, University Hospital, Nottingham and not at Southampton as stated. 